\title{
Advances in the Genetics of Congenital Ptosis
}

\author{
Peixuan Wu $\mathrm{W}^{\mathrm{a}}$ Jing Mab, c Tianyu Zhang ${ }^{\mathrm{b}, \mathrm{c}, \mathrm{d}}$ Duan Maa,e
}

aKey Laboratory of Metabolism and Molecular Medicine, Ministry of Education, Department of Biochemistry and

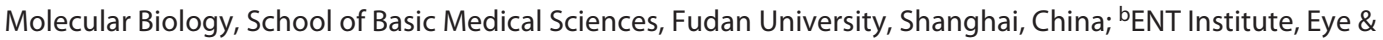
ENT Hospital, Fudan University, Shanghai, China; 'Department of Facial Plastic and Reconstructive Surgery, Eye \& ENT Hospital, Fudan University, Shanghai, China; ${ }^{d} \mathrm{NHC}$ Key Laboratory of Hearing Medicine (Fudan University), Shanghai, China; 'Research Center for Birth Defects, Children's Hospital, Fudan University, Shanghai, China

\section{Keywords}

Congenital ptosis · Birth defect · Genetics · Levator palpebrae superioris

\begin{abstract}
Congenital ptosis, a birth defects presents at birth or by 1 year of age, is characterized by the drooping of the upper eyelid. Either in isolation (nonsyndromic) or with many different systemic disorders (syndromic). The estimated prevalence of ptosis (congenital and acquired) ranges from 0.79 to 1.99 per 10,000 people in different populations, and it is more prevalent in males. The underlying pathogenesis of congenital ptosis is myogenic and neurogenic, related to the development of muscles and nerves. Although most cases are sporadic, there are familial transmission characteristics, including autosomal dominant, recessive mode, and X-linkage inheritance patterns. Moreover, some forms are due to chromosomal aberrations and mutations and deletions in mitochondrial DNA. Genes involved in simple congenital ptosis (SCP) are ZFHX4 and COL25A1. The clinical aspects of various syndromes involving congenital ptosis are partly caused by single-gene mutations. However, the pathogenesis of congenital ptosis is not fully understood. We review the reported epidemiology, genetics, and clinical features of congenital ptosis and associated syndromes here.
\end{abstract}

C 2021 The Author(s)

Published by S. Karger AG, Basel

\section{Introduction}

Blepharoptosis, abbreviated as ptosis, includes both congenital and acquired conditions. Congenital ptosis (OMIM \%178300, OMIM \%300245), a birth defect defined as ptosis present at birth or by 1 year of age, is characterized by the drooping of the upper eyelid. It is generally due to myogenic factors or innervation abnormalities, resulting in narrowing of the vertical dimension of the palpebral fissure and even partial or complete occlusion of vision [1-3]. Congenital ptosis is the most common type of ptosis in childhood and seems to be more prevalent in males. The estimated prevalence of ptosis (congenital and acquired) varies between 0.79 and 1.99 per 10,000 people in different populations (Table 1) $[4,5]$. The prevalence of congenital ptosis in China was found to be $0.18 \%$, based on mass screening of 247,389 people [6]. Although most congenital cases internationally and in China are sporadic (nonhereditary), related to environmental factors affecting the embryo, there are familial transmission characteristics (11.7-19.4\%). Ptosis (congenital and acquired) can occur unilaterally or bilaterally. The unilateral form is much more common, occurring in $63-91.5 \%$ of cases. In unilateral cases, the left side is more often affected. The general characteristics of ptosis in various populations are summarized in Table 1 [7-10].

The normal adult upper lid margin is $0.5-2 \mathrm{~mm}$ below the superior corneal limbus and the levator func- karger@karger.com www.karger.com/ore Karger $\stackrel{\text { ' }}{=}$ GOPEN ACCESS
(C) 2021 The Author(s)

Published by S. Karger AG, Basel

This is an Open Access article licensed under the Creative Commons Attribution-NonCommercial-4.0 International License (CC BY-NC) (http://www.karger.com/Services/OpenAccessLicense), applicable to the online version of the article only. Usage and distribution for commercial purposes requires written permission.
Correspondence to:

Tianyu Zhang, ty.zhang2006@aliyun.com

Duan Ma,duanma@fudan.edu.cn 
Table 1. Characteristics of ptosis (congenital and acquired) in various populations

\begin{tabular}{|c|c|c|c|c|c|c|c|c|c|}
\hline Patients, $n$ & Prevalence & Congenital, $\%$ & Nonsyndromic, \% & Unilateral, \% & Laterality, \% & Sex ratio, \% & Familial, \% & Origin of patients & Ref \\
\hline 2,328 & - & 78 & 73.7 & 63 & $52.2, \mathrm{~L}$ & $57.4, M$ & - & Korea & [7] \\
\hline 155 & & - & 65.2 & 47.7 & - & $68.4, M$ & 32.9 & China & - \\
\hline 155 & - & - & 49 & 80 & $54.2, \mathrm{R}$ & $60, M$ & 16.77 & Birmingham, UK & [9] \\
\hline 107 & $7.9 / 100,000$ & 89.7 & 75.7 & 91.5 & $68.4, \mathrm{~L}$ & $55, \mathrm{M}$ & 11.7 & Minnesota, USA & [4] \\
\hline
\end{tabular}

$M$, male; $F$, female; $L$, left; $R$, right; Ref, reference.

tion is usually normal (12-15 mm). According to its severity, upper eyelid ptosis can be mild (upper eyelid droop 1-2 $\mathrm{mm}$ ), moderate (3-4 $\mathrm{mm}$ ), or severe ( $>4$ $\mathrm{mm})$. Generally, mild ptosis is associated with good levator function (measured by upper eyelid excursion as a patient looks from downgaze to upgaze, $>8 \mathrm{~mm}$ ), moderate ptosis with fair levator function $(5-7 \mathrm{~mm})$, and severe ptosis with poor levator function (1-4 mm) $[11,12]$.

In some cases, congenital ptosis occurs as an isolated condition (nonsyndromic congenital ptosis [NSCP]) that makes patients a tired appearance without affecting their health. Familial inheritance patterns of NSCP include autosomal dominant inheritance, autosomal recessive inheritance, and X-linked dominant inheritance. Generally, but not in all cases, patients may have strabismus and eyestrain may be secondary to visual occlusion and disruption by the ptotic eyelid [13]. Other ocular symptoms include astigmatism due to eyelid tension and changes in the corneal curvature [14], amblyopia due to astigmatic anisometropia or deprivation [1], and headaches due to forced brow elevation to increase the visual field. The prevalence (14.9\%) of amblyopia in patients with congenital ptosis is higher than that in the general population $[15,16]$. In other cases, congenital ptosis may occur in conjunction with various other conditions in syndromic form (syndromic congenital ptosis [SCP]). In addition to causing visual impairment, SCP also warns of a more severe condition in other systems of the body, such as myasthenia gravis, myotonia congenita, mitochondrial myopathies, and so on [12,17]. In addition to this, ptosis can cause cosmetic disfigurement, resulting in psychological disorders in patients. Most cases of SCP with familial transmission characteristics are caused by mutations of a single-gene resulting in deficient function of muscle and nerve. The focus of this review is to discuss the genetic aspects of congenital ptosis and associated syndromes.

\section{Anatomy}

The upper eyelids are composed of several structures. Commonly, these structures are divided into anterior, middle, and posterior lamellae [18].

The anterior lamella refers to the skin and orbicularis oculi muscle of the eyelid. Below the skin of the upper eyelid lies the orbicularis oculi muscle which be divided into orbital and palpebral portions. The former consists of concentric muscle fibers and it functions to close the eyes tightly. The latter consists of semilunar muscle fibers. The posterior lamella refers to the retractors, superior tarsal muscle, tarsus, and the conjunctiva. The levator palpebrae superioris (LPS) and Müller's muscle are the retractor muscles of the upper eyelid. The LPS, a striated muscle, is innervated by the superior division of the oculomotor nerve (cranial nerve III) and controls lid opening [12]. The superior tarsal muscle, or Müller's muscle, lies deep in the levator aponeurosis. This smooth muscle contributes to the resting tone of the upper eyelid, providing about $2-3 \mathrm{~mm}$ of upper eyelid elevation, and is innervated by sympathetic fibers [12]. Some researchers also reference the orbital septum as the middle lamella. Deep in the orbital septum lie the postseptal orbital fat pads which are traditionally divided into the central (preaponeurotic) and medial (nasal) fat pads. The former serves as a gliding surface for the levator muscle and aponeurosis [18]. Summarily, the normal development of muscles and nerves is necessary for the upper eyelid to maintain normal function.

\section{Histopathology}

The LPS is the major elevator of the upper eyelid. Normal muscle fibers of LPS are elongated and arranged in parallel bundles, and the nuclei are at the periphery. The nuclear membrane is clear and complete with homoge- 
neous chromatin. However, LPS from NSCP individuals has contained a primary defect in the muscle, with fibrosis, a reduction or disruption of myofibers, fat infiltration, and internalization of nuclei. Some authors have noted an inverse correlation between the degree of ptosis and the number of residual striated muscle fibers. Scanty and atrophic remaining striated muscles [19], inflammatory cells, abnormal mitochondria (megamitochondria, mitochondrial matrix alterations, and abnormal cristae) [20], and amorphous extracellular material [21] have also been reported. At present, there are two opinions concerning the pathological change in the LPS in congenital ptosis, dystrophic (an inherited disease with progressive muscle weakness and wasting), and dysgenesis (a defect in the development of the muscle) [22]. However, the specific pathological description is still insufficiently clear, leading to considerable confusion regarding the basic pathogenesis of congenital ptosis.

The prominent features of Müller's muscle (the superior tarsal muscle) specimens with congenital ptosis are the reduction of the muscle fibers, cytoplasmic vacuoles containing flocculent material, degraded nuclear chromatin, and indistinct nuclear membranes in myocytes. All of this demonstrated a widespread atrophic pattern in the Müller's muscle [23].

\section{Genetics of NSCP}

NSCP is the most prevalent form of congenital ptosis. Its pathogenesis is presumably multifactorial. Vestal et al. [24], using all available twin data including monozygotic and dizygotic twins with unilateral or bilateral congenital ptosis, found a heritability index of 0.75 , indicating that $75 \%$ of the phenotype is attributable to genetic factors. In addition to this, clinical heterogeneity is a major feature of hereditary congenital ptosis. One case study reported 4-year-old monozygotic twins with incomplete concordance for NSCP (one bilateral, one unilateral) [25]. Another case reported a large family affected by autosomal dominant NSCP with $70-90 \%$ penetrance. These patients display NSCP which in some patients is unilateral and in some bilateral, some symmetric and some asymmetric, some with levator-abducens and medial rectus-orbicularis synkinetic activation and some with no such activation. The author suggests the possibility of a modifier gene determining laterality of ptosis [26]. The presence of occasional discordance in twins and variable penetrance in familial cases may also suggest a more complicated, possibly multifactorial, genetic defect, or an environmental influence.

Genetics of Congenital Ptosis
The candidate gene of NSCP that has been identified is rare. The $Z F H X 4 / Z F H-4$ gene, located at chromosome $8 \mathrm{q} 21.13$, encodes a 3,567-amino acid protein with a zincfinger homeodomain that acts as a transcription factor, one of the important gene types that cause developmental diseases. ZFHX4 was found to be a candidate gene following DNA analysis of a child with bilateral NSCP who has a balanced translocation of chromosomes $t(1 ; 8)$ (p34.3;q21.12). The breakpoint in chromosome 8 was found to disrupt the ZFHX4 gene located at 8q21.12 [27]. The missense alteration G12411T and L4137F in ZFHX4 gene in children can cause the occurrence of congenital ptosis [28]. Study has also shown that ZFHX4 is involved in muscle and neural differentiation (affecting the structure and function of the oculomotor cranial nerve nuclei) [29]. Mouse $Z f h x 4$ expression is prominent in developing muscle and brain (especially in the midbrain, in which the oculomotor nuclei are situated). In both tissues, $Z f h \times 4$ RNA levels are highest embryonically, then decrease gradually to barely detectable levels in adults [30]. Future work is required to look at the ZFHX4 gene in other patients with NSCP to find mutations that would indicate causality.

COL25A1, located at chromosome 4q25, encodes a 654-amino acid brain-specific membrane-bound collagen expressed in the oculomotor and abducens nerves. Studies have shown that a COL25A1 recessive mutation is the pathogenic factor in two children with NSCP (one unilateral, one bilateral) [31]. Recessive COL25A1 mutations lead to not only decreased levels of COL25A1 expression but also, apparently, decreased levels of certain molecules involved in developmental axonal guidance. Therefore, the lack of COL25A1 expression might interfere with molecular pathways involved in oculomotor neuron development, leading to congenital cranial dysinnervation disorders phenotypes [32]. In experimental animals, Col25a1 is involved in early myogenesis and plays a key role in myoblast fusion. Col25a $1^{-1-}$ mice exhibit a delay in the fusion and organization of myofibers during primary myogenesis [33]. However, the associated ophthalmic phenotype has not been specified. Further study is needed to understand how frequently recessive $\mathrm{CO}$ L25A1 mutations underlie these specific ocular phenotypes.

Genetic research can provide an important basis for the diagnosis and treatment of congenital ptosis. However, the relative roles of environmental and genetic influences during embryonic development are not known. The contributions to pathogenesis remain to be completely elucidated.

Ophthalmic Res 2022;65:131-139 


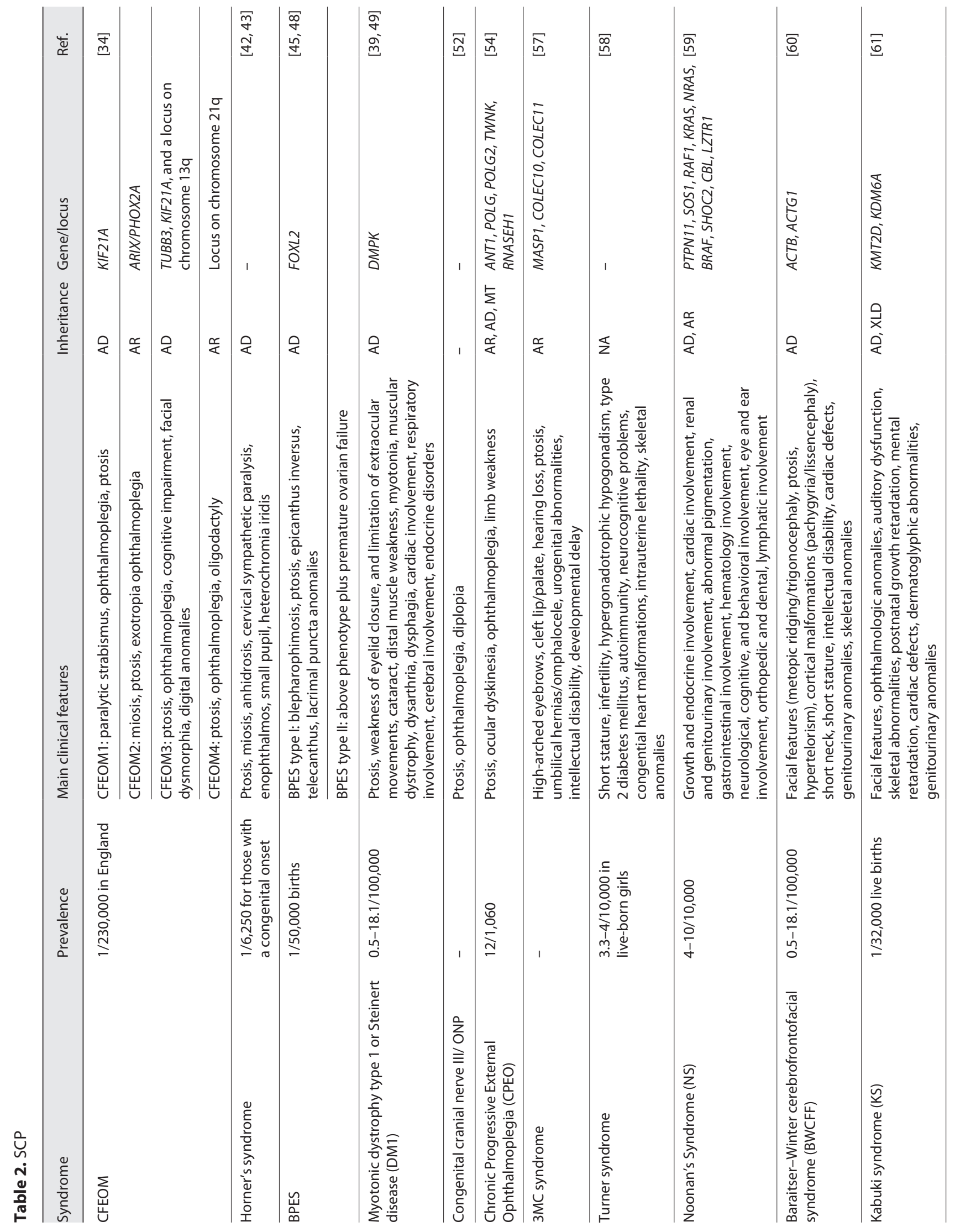




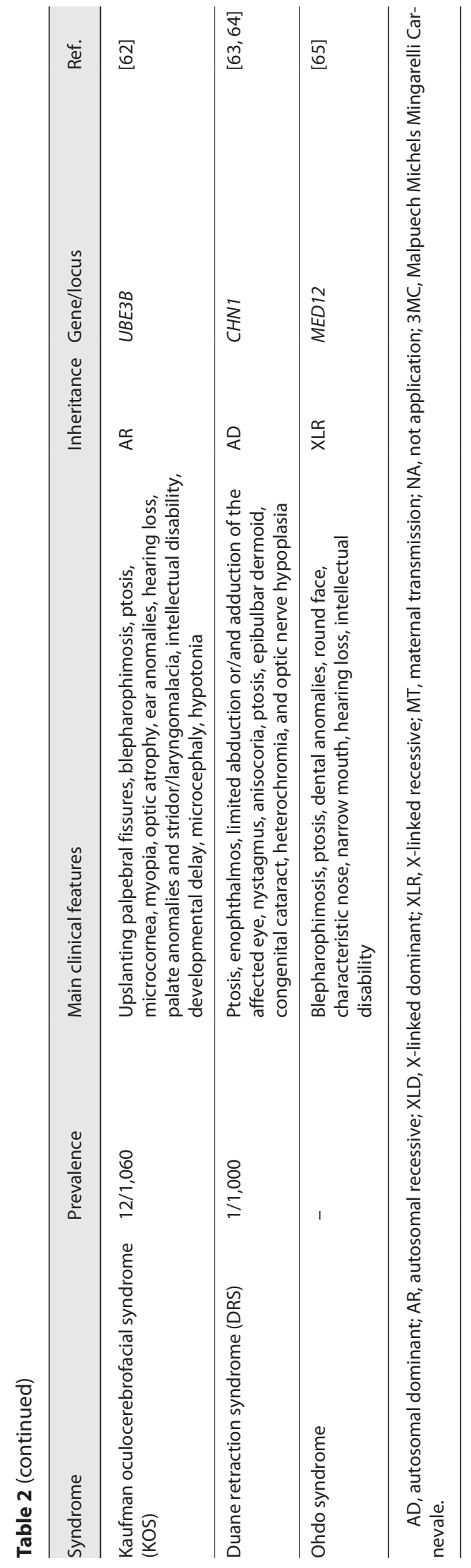

Genetics of Congenital Ptosis

\section{Syndromic Congenital Ptosis}

Around $25-51 \%$ of patients with ptosis have additional abnormalities. According to the incidence rate, the following syndromes were selected for discussion (Table 2).

\section{Congenital Fibrosis of the Extraocular Muscles}

Congenital fibrosis of the extraocular muscles (CFEOM) is a group of conditions characterized by congenital paralytic strabismus secondary to restrictive ophthalmoplegia with accompanying congenital ptosis, also known as a subset of a group of disorders called the congenital cranial dysinnervation disorders, which primarily affects ocular motility. These disorders are caused by abnormal development of the innervation of extraocular muscles [34]. The reported prevalence of CFEOM in England is $1 / 230,000$. CFEOM is relatively commonly associated with a genetic defect, and genotypic heterogeneity exists. According to ophthalmic findings and genetic differences, the subtypes of CFEOM are described as follows.

CFEOM1 (OMIM \#135700) is an autosomal dominant condition and results primarily from heterozygous mutations in KIF21A located on chromosome 12q12. KIF21A encodes a 1,674-amino acids kinesin protein that has high levels of expression in neurons and works as an inhibitor of microtubule growth at the cell cortex [34]. Yamada et al. [35] first identified a p.R954W substitution (the most frequent mutation) in KIF21A as the cause of CFEOM1. The mutation of KIF21A in axonal growth cones can induce misregulation of MT dynamics, and the associated changes in axonal morphology and guidance may form the basis of CFEOM1 pathogenesis [36]. Affected individuals present atrophy of the levator palpebrae and superior rectus muscle, leading to severely restricted eye elevation (inability to raise the eyes above the midline) and severe bilateral congenital ptosis.

CFEOM2 (OMIM \#602078) is an autosomal recessive condition. The homozygous mutation in the ARIX/ $P H O X 2 A$ gene was first identified in patients with CFEOM2 [37]. The ARIX/PHOX2A gene, located on chromosome 11q13.4, encodes a 284-amino acid transcription factor that plays a central role in development of the autonomic nervous system. Affected individuals present severe bilateral congenital ptosis, exotropia ophthalmoplegia, and occasionally miosis. ARIX/PHOX2A has been shown to be essential to the development of the oculomotor and trochlear nuclei in mice and zebrafish [38]. 
CFEOM3 is an autosomal dominant condition with incomplete penetrance that can lead to a heterogeneous phenotype characterized by congenital ptosis, ranging from mild to severe, ophthalmoplegia, cognitive impairment, facial dysmorphia, and/or digital anomalies [34, 39]. The causative mutation has been found in the TUBB3 gene located on chromosome 16q24 (CFEOM3A, OMIM \#600638), the KIF21A gene (CFEOM3B), and a locus on 13q (CFEOM3C, OMIM \%609384). TUBB3 encodes a class III member of the beta tubulin protein family that is primarily expressed in neurons and may be involved in neurogenesis and axon guidance and maintenance. $\mathrm{Hu}-$ man TUBB3 mutations perturb microtubule dynamics, kinesin interactions, and axon guidance [40].

CFEOM4 (OMIM \%609428), also known as Tukel syndrome, is an autosomal recessive condition. Affected individuals display eye and hand anomalies, and there is established linkage to a locus on chromosome 21q [41].

\section{Horner's Syndrome}

Horner's syndrome (OMIM \%143000) results from a disruption in the sympathetic nervous system, producing the classic triad of ipsilateral congenital ptosis, miosis, and anhidrosis. The congenital ptosis seen in Horner's syndrome is mild, typically on the order of $1-2 \mathrm{~mm}$, and is due to dysfunction of the sympathetically innervated Müller's muscle [1]. It is important as a warning sign that the oculosympathetic pathway has been interrupted, potentially by serious and even life-threatening processes. The prevalence of Horner's syndrome was reported to be $1.42 / 100,000$ in patients younger than 19 years, with a birth prevalence of $1 / 6,250$ for those with a congenital onset [42]. Autosomal dominant inheritance of congenital Horner's syndrome has been reported in family cases [43]. However, genetic studies have been very scarce to date.

\section{Blepharophimosis Ptosis Epicanthus Inversus Syndrome}

Blepharophimosis ptosis epicanthus inversus syndrome (BPES, OMIM \#110100) is a rare inheritable disease that occurs sporadically or in association with autosomal dominant mutations, with an estimated incidence of 1 in 50,000 births. Affected individuals present horizontal narrowing of the eye opening (blepharophimosis), drooping upper eyelids (congenital ptosis), a skin fold arising upwards and inwards from the lower eyelid (epicanthus inversus), telecanthus, and lacrimal puncta anomalies, such as lateral displacement or stenosis. Apart from ophthalmic symptoms, female patients may suffer premature ovarian failure (BPES type I) or not (BPES type II) [39].
At least $88 \%$ of patients with BPES types I and II present a mutation or a deletion of FOXL2 coding or regulatory sequences [44]. FOXL2, located on chromosome $3 q 22.3$, encodes a 376-amino acid forkhead transcription factor localized in the nucleus and transcriptionally modulates genetic programs required for early eyelid development and ovary differentiation and maintenance. Mouse Foxl2 has been shown to be expressed by both cranial neural crest cells (CNCCs) and cranial mesodermal cells (CMCs), and is required for correct periocular muscle and bone morphogenesis. Using selective inactivation of Foxl 2 in CNCCs or in CMCs, CNCCs provide the topological cues needed for the morphogenesis of certain CMC-derived extraocular muscles such as the LPS or the oblique muscles [44]. A collection of more than 100 genetic alterations affecting the FOXL2 locus have been identified in patients with BPES, including frameshifts, insertions, nonsense or missense mutations, microdeletion in a cis-regulatory element [45] and copy number changes [46], with intragenic mutations accounting for the majority (71\%). Mice lacking FoxL2 exhibit craniofacial anomalies, including eye-open at birth and ovarian malformations, with high rates of perinatal mortality [47]. Notch1 activation may serve as the upstream control of Foxl2 expression by periocular mesenchymal cells, which are destined for levator smooth muscle development of the eyelids [48].

\section{Myotonic Dystrophy Type 1 or Steinert Disease}

Myotonic dystrophy can be divided into two types: type 1 (DM1, OMIM \#160900) is congenital. Its prevalence ranges between 0.5 and 18.1 per 100,000 people, making it the most common muscular dystrophy. The clinical condition includes distal muscle weakness, myotonia, muscular dystrophy, dysarthria, dysphagia, facial weakness (congenital ptosis, weakness of eyelid closure, and limitation of extraocular movements), posterior iridescent cataracts, cardiac or respiratory involvement, cerebral involvement, and endocrine disorders [39, 49].

DM1 is a dominantly inherited disorder caused by an expansion of an unstable CTG trinucleotide repeat in the $3^{\prime} \mathrm{UTR}$ of the DMPK gene located on chromosome 19q13.32, which encodes a 629-amino acid serine-threonine kinase that is necessary for the maintenance of skeletal muscle structure and function. A repeat length exceeding 50 CTG repeats is pathogenic [50]. Most evidence implies that a major pathogenic consequence of expanded CTG repeats in DM1 is the formation of hairpin structures that bind and sequester RNA-binding proteins [51]. 
Congenital Cranial Nerve III/Oculomotor Nerve Palsy

Congenital cranial nerve III/oculomotor nerve palsy is a clinical diagnosis, which mostly presents with congenital ptosis and ophthalmoplegia, which may result in diplopia [52]. The superior division cranial nerve 3 (CN3) innervates the ipsilateral superior rectus and LPS muscles. Lesions affecting cranial nerve 3 may occur anywhere along its path between the brainstem and the extraocular muscles and can result in either partial or complete third nerve palsy [53]. Partial third nerve palsies may affect only one of the divisions or only certain nerve fibers. Pupillary response may be intact, poor, or absent, depending on the lesion. In cases in which a mild anisocoria is present, it will be more apparent in brighter light than in the dark. No related genes and locis have been reported.

\section{Chronic Progressive External Ophthalmoplegia}

Chronic Progressive External Ophthalmoplegia (CPEO, OMIM \#616479) is a type of mitochondrial myopathy with a low prevalence $(12 / 1,060)$ [54]. Patients with CPEO may present with bilateral congenital ptosis, usually symmetric ocular motility deficit, complete ophthalmoplegia with no restrictions on forced ductions, and orbicularis oculi weakness. Patients may have onset of this disease at any age. CPEO is characterized by remarkable genetic heterogeneity. The inheritance pattern follows autosomal recessive, autosomal dominant, and maternal transmission pattern. Increasing evidence implicates the role of mitochondrial genetics and most cases of CPEO are the result of mitochondrial DNA (mtDNA) deletions [55], including mtDNA point mutations, a single large-scale mtDNA deletions, duplications or multiple mtDNA deletions, secondary to nuclear mutations to genes including ANT1, POLG, POLG2, TWNK, and RNASEH1. In CPEO medial rectus tissue, there are focal areas of disruption and abnormal mitochondria and selective vacuolization [56].

Ptosis occurs in association with other malformations such as Malpuech Michels Mingarelli Carnevale syndrome [57], Turner syndrome [58], Noonan syndrome [59], Baraitser-Winter cerebrofrontofacial syndrome [60], Kabuki syndrome [61], Kaufman oculocerebrofacial syndrome [62], Duane retraction syndrome [63, 64], Ohdo syndrome [65], and so on. Mutations in the RYR1 [66] and ECEL1 [67] genes can also cause SCP. These are rare conditions that are not discussed in this article. In the clinical assessment of a patient with congenital ptosis, looking for associated anomalies is important because, if they are present, attributing them to a known syndrome could be crucial.

Genetics of Congenital Ptosis

\section{Other Genetic Factors in Congenital Ptosis}

There have also been reports of chromosomal structural changes leading to congenital ptosis. A case of de novo $18 \mathrm{p}$ deletion syndrome with panhypopituitarism with a feature of congenital ptosis revealed a de novo deletion on the short arm of chromosome 18 [68]. Interstitial duplications of Xq25-q26 exhibit a recognizable microduplication syndrome comprising a remarkable facial appearance with congenital bilateral ptosis, cleft palate and large protruding ears, accompanied by genital and digital defects [69]. Partial trisomies of the short arm of chromosome 6 lead to craniofacial dysmorphism, choanal atresia, congenital ptosis, sensorineural hearing loss, heart defects, developmental delay, and renal dysfunction [70].

In addition, mutations and deletions in mtDNA are a recurrent cause of metabolic and neuromuscular abnormalities. Single large-scale mtDNA deletions are amongst the most frequently diagnosed mtDNA disorders in childhood. The most frequent initial presentation in patients with childhood-onset mitochondrial disease caused by single large-scale mtDNA deletions is congenital ptosis $(16 / 34,47 \%)$ [71].

Epigenetic regulation of gene expression, through covalent modification of histones, is a key process controlling growth and development. $\mathrm{H} 3$ acetylation is important for neural, craniofacial, and skeletal morphogenesis, mainly through its ability specifically to regulate the MAPK signaling pathway [72]. Mattioli et al. [73] reported that a frameshift in $B R P F 1$, encoding a protein modifieroftwohistoneacetyltransferases, KAT6A/MOZ/MYST3 and $K A T 6 B / M O R F / M Y S T 4$, can lead to an intellectual disability syndrome with congenital ptosis. The protein variant shows an aberrant cellular location, loss of certain protein interactions, and decreased histone H3K23 acetylation.

\section{Conclusion}

Congenital ptosis is an ophthalmologic condition worldwide that is related to muscle and nerve development. If left untreated, it can have an impact on physical and mental health. More studies with larger families of cases are clearly required, and the establishment of a biobank should be standardized. In addition to this, the etiology of myogenic congenital ptosis needs to be further elucidated. CMCs are at the origin of craniofacial muscles and some posterior skeletal elements of the skull, playing

Ophthalmic Res 2022;65:131-139 
a key role in craniofacial development. Thus, studies of embryonic development may open new lines of thought. Further study of genetics may be helpful and provide a basis for a classification of congenital ptosis. However, the genetic and epigenetic research progress has been very scarce to date. New genes and loci remain to be identified. Understanding the genetics and epigenetic regulatory modification of congenital ptosis will provide tools for appropriate genetic counseling, and molecular genetic testing can be helpful in confirming an exact diagnosis. Continued research and insight are necessary to advance our understanding to create new and promising treatment modalities.

\section{Conflict of Interest Statement}

The authors have no conflicts of interest to declare.

\section{Funding Sources}

This manuscript did not receive any funding.

\section{Author Contributions}

All authors contributed to the Proposing of the topic and design of content. The first draft of the manuscript was written by Peixuan $\mathrm{Wu}$ and all authors commented on previous versions of the manuscript. All authors read and approved the final manuscript.

\section{References}

1 SooHoo JR, Davies BW, Allard FD, Durairaj VD. Congenital ptosis. Surv Ophthalmol. 2014;59(5):483-92.

2 Sakol PJ, Mannor G, Massaro BM. Congenital and acquired blepharoptosis. Curr Opin Ophthalmol. 1999;10(5):335-9.

3 McMullan TF, Robinson DO, Tyers AG. Towards an understanding of congenital ptosis. Orbit. 2006;25(3):179-84.

4 Griepentrog GJ, Diehl NN, Mohney BG. Incidence and demographics of childhood ptosis. Ophthalmology. 2011;118(6):11803.

5 Nemet AY, Segal O, Mimouni M, Vinker S. Associated morbidity of pediatric ptosis: a large, community based case-control study. Graefes Arch Clin Exp Ophthalmol. 2014; 252(9):1509-14.

$6 \mathrm{Hu}$ DN. Prevalence and mode of inheritance of major genetic eye diseases in China. J Med Genet. 1987;24(10):584-8.

7 Lee YG, Son BJ, Lee KH, Lee SY, Kim CY. Clinical and demographic characteristics of blepharoptosis in Korea: a 24-year experience including 2,328 patients. Korean J Ophthalmol. 2018;32(4):249-56.

8 Pavone P, Garozzo R, Trifiletti RR, Parano E. Marin-Amat syndrome: case report and review of the literature. J Child Neurol. 1999; 14(4):266-8.

9 El Essawy R, Elsada MA. Clinical and demographic characteristics of ptosis in children: a national tertiary hospital study. Eur J Ophthalmol. 2013;23(3):356-60.

10 Berry-Brincat A, Willshaw H. Paediatric blepharoptosis: a 10-year review. Eye. 2009; 23(7):1554-9.

11 Patel K, Carballo S, Thompson L. Ptosis. Dis Mon. 2017;63(3):74-9.

12 Finsterer J. Ptosis: causes, presentation, and management. Aesthetic Plast Surg. 2003; 27(3):193-204.

13 Griepentrog GJ, Mohney BG. Strabismus in childhood eyelid ptosis. Am J Ophthalmol. 2014;158(1):208-10.e1.
14 Wang Y, Xu Y, Liu X, Lou L, Ye J. Amblyopia, strabismus and refractive errors in congenital ptosis: a systematic review and meta-analysis. Sci Rep. 2018;8(1):8320.

15 Zhang JY, Zhu XW, Ding X, Lin M, Li J. Prevalence of amblyopia in congenital blepharoptosis: a systematic review and meta-analysis. Int J Ophthalmol. 2019;12(7): 1187-93

16 Griepentrog GJ, Diehl N, Mohney BG. Amblyopia in childhood eyelid ptosis. Am J Ophthalmol. 2013;155(6):1125-8.e1.

17 Shahzad B, Siccardi MA. Ptosis. In: StatPearls [Internet]. Treasure Island, FL: StatPearls Publishing; 2020.

18 Sand JP, Zhu BZ, Desai SC. Surgical anatomy of the eyelids. Facial Plast Surg Clin North Am. 2016;24(2):89-95.

19 Nakashima M, Nakano M, Hirano A, Kishino T, Kondoh S, Miwa N, et al. Genomewide linkage analysis and mutation analysis of hereditary congenital blepharoptosis in a Japanese family. J Hum Genet. 2008;53(1): 34-41.

20 Wabbels B, Schroeder JA, Voll B, Siegmund $\mathrm{H}$, Lorenz B. Electron microscopic findings in levator muscle biopsies of patients with isolated congenital or acquired ptosis. Graefes Arch Clin Exp Ophthalmol. 2007;245(10): 1533-41.

21 Clark BJ, Kemp EG, Behan WM, Lee WR. Abnormal extracellular material in the levator palpebrae superioris complex in congenital ptosis. Arch Ophthalmol. 1995;113(11): 1414-9.

22 Surve A, Sharma MC, Pushker N, Bajaj MS, Meel R, Kashyap S. A study of changes in levator muscle in congenital ptosis. Int Ophthalmol. 2019;39(6):1231-8.

23 Alshehri MD, Al-Fakey YH, Alkhalidi HM, Mubark MA, Alsuhaibani AH. Microscopic and ultrastructural changes of Müller's muscle in patients with simple congenital ptosis. Ophthalmic Plast Reconstr Surg. 2014;30(4): 337-41.
24 Vestal KP, Seiff SR, Lahey JM. Congenital ptosis in monozygotic twins. Ophthalmic Plast Reconstr Surg. 1990;6(4):265-8.

25 Stackhouse JR, Escaravage GK Jr, Dutton JJ. Monozygotic twins with incompletely concordant simple congenital ptosis in a 4-generation pedigree. Ophthalmic Plast Reconstr Surg. 2009;25(6):493-4.

26 Pavone P, Barbagallo M, Parano E, Pavone L, Souayah N, Trifiletti RR. Clinical heterogeneity in familial congenital ptosis: analysis of fourteen cases in one family over five generations. Pediatr Neurol. 2005;33(4): 251-4.

27 McMullan TW, Crolla JA, Gregory SG, Carter NP, Cooper RA, Howell GR, et al. A candidate gene for congenital bilateral isolated ptosis identified by molecular analysis of a de novo balanced translocation. Hum Genet. 2002; 110(3):244-50.

28 Adhikari S, Thakur N, Shrestha U, Shrestha MK, Manshrestha M, Thapa B, et al. Genetic analysis of children with congenital ocular anomalies in three ecological regions of $\mathrm{Ne}$ pal: a phase II of Nepal pediatric ocular diseases study. BMC Med Genet. 2020;21(1):185.

29 Hemmi K, Ma D, Miura Y, Kawaguchi M, Sasahara M, Hashimoto-Tamaoki T, et al. A homeodomain-zinc finger protein, ZFHX4, is expressed in neuronal differentiation manner and suppressed in muscle differentiation manner. Biol Pharm Bull. 2006;29(9):1830-5.

30 Kostich WA, Sanes JR. Expression of zfh-4, a new member of the zinc finger-homeodomain family, in developing brain and muscle. Dev Dyn. 1995;202(2):145-52.

31 Khan AO, Al-Mesfer S. Recessive COL25A1 mutations cause isolated congenital ptosis or exotropic Duane syndrome with synergistic divergence. J AAPOS. 2015;19(5):463-5.

32 Shinwari JM, Khan A, Awad S, Shinwari Z, Alaiya A, Alanazi M, et al. Recessive mutations in COL25A1 are a cause of congenital cranial dysinnervation disorder. Am J Hum Genet. 2015;96(1):147-52. 
33 Gonçalves TJM, Boutillon F, Lefebvre S, Goffin $\mathrm{V}$, Iwatsubo T, Wakabayashi T, et al. Collagen XXV promotes myoblast fusion during myogenic differentiation and muscle formation. Sci Rep. 2019;9(1):5878.

34 Price JM, Boparai RS, Wasserman BN. Congenital fibrosis of the extraocular muscles: review of recent literature. Curr Opin Ophthalmol. 2019;30(5):314-8.

35 Yamada K, Andrews C, Chan WM, McKeown CA, Magli A, de Berardinis T, et al. Heterozygous mutations of the kinesin KIF21A in congenital fibrosis of the extraocular muscles type 1 (CFEOM1). Nat Genet. 2003;35(4): 318-21.

36 van der Vaart B, van Riel WE, Doodhi H, Kevenaar JT, Katrukha EA, Gumy L, et al. CFEOM1-associated kinesin KIF21A is a cortical microtubule growth inhibitor. Dev Cell. 2013;27(2):145-60.

37 Nakano M, Yamada K, Fain J, Sener EC, Selleck CJ, Awad AH, et al. Homozygous mutations in ARIX(PHOX2A) result in congenital fibrosis of the extraocular muscles type 2 . Nat Genet. 2001;29(3):315-20.

38 Guo S, Brush J, Teraoka H, Goddard A, Wilson SW, Mullins MC, et al. Development of noradrenergic neurons in the zebrafish hindbrain requires BMP, FGF8, and the homeodomain protein soulless/Phox2a. Neuron. 1999; 24(3):555-66.

39 Diaz-Manera J, Luna S, Roig C. Ocular ptosis: differential diagnosis and treatment. Curr Opin Neurol. 2018;31(5):618-27.

40 Tischfield MA, Baris HN, Wu C, Rudolph G, Van Maldergem L, He W, et al. Human TUBB3 mutations perturb microtubule dynamics, kinesin interactions, and axon guidance. Cell. 2010;140(1):74-87.

41 Tukel T, Uzumcu A, Gezer A, Kayserili $\mathrm{H}$, Yuksel-Apak M, Uyguner O, et al. A new syndrome, congenital extraocular muscle fibrosis with ulnar hand anomalies, maps to chromosome 21qter. J Med Genet. 2005;42(5):40815.

42 Smith SJ, Diehl N, Leavitt JA, Mohney BG Incidence of pediatric Horner syndrome and the risk of neuroblastoma: a populationbased study. Arch Ophthalmol. 2010;128(3): 324-9.

43 Hageman G, Ippel PF, te Nijenhuis FC. Autosomal dominant congenital Horner's syndrome in a Dutch family. J Neurol Neurosurg Psychiatry. 1992;55(1):28-30.

44 Heude É, Bellessort B, Fontaine A, Hamazaki M, Treier AC, Treier M, et al. Etiology of craniofacial malformations in mouse models of blepharophimosis, ptosis and epicanthus inversus syndrome. Hum Mol Genet. 2015; 24(6):1670-81.

45 Bouman A, van Haelst M, van Spaendonk R. Blepharophimosis-ptosis-epicanthus inversus syndrome caused by a $54-\mathrm{kb}$ microdeletion in a FOXL2 cis-regulatory element. Clin Dysmorphol. 2018;27(2):58-62.
46 D'Haene B, Nevado J, Pugeat M, Pierquin G, Lowry RB, Reardon W, et al. FOXL2 copy number changes in the molecular pathogenesis of BPES: unique cohort of 17 deletions. Hum Mutat. 2010;31(5):E1332-47.

47 Liu CY. Wakayama symposium: NotchFoxL2- $\alpha$-SMA axis in eyelid levator muscle development and congenital blepharophimosis. Ocul Surf. 2012;10(4):221-3.

48 Zhang Y, Kao WW, Pelosi E, Schlessinger D, Liu CY. Notch gain of function in mouse periocular mesenchyme downregulates FoxL2 and impairs eyelid levator muscle formation, leading to congenital blepharophimosis. J Cell Sci. 2011;124(Pt 15):2561-72.

49 Nguyen CE, Campbell C. Myotonic dystrophy type 1. CMAJ. 2016;188(14):1033.

50 Musova Z, Mazanec R, Krepelova A, Ehler E, Vales J, Jaklova R, et al. Highly unstable sequence interruptions of the CTG repeat in the myotonic dystrophy gene. Am J Med Genet A. $2009 ; 149 \mathrm{~A}(7): 1365-74$.

51 Meola G. Clinical aspects, molecular pathomechanisms and management of myotonic dystrophies. Acta Myol. 2013;32(3):154-65.

52 Raza HK, Chen H, Chansysouphanthong T, Cui G. The aetiologies of the unilateral oculomotor nerve palsy: a review of the literature. Somatosens Mot Res. 2018;35(3-4):229-39.

53 Bagheri A, Borhani M, Salehirad S, Yazdani S, Tavakoli M. Blepharoptosis associated with third cranial nerve palsy. Ophthalmic Plast Reconstr Surg. 2015;31(5):357-60.

54 Lv H, Qu Q, Liu H, Qian Q, Zheng X, Zhang Y. Clinical, neuroelectrophysiological and muscular pathological analysis of chronic progressive external ophthalmoplegia. Exp Ther Med. 2020;20(2):1770-4.

55 Lee AG, Brazis PW. Chronic progressive external ophthalmoplegia. Curr Neurol Neurosci Rep. 2002;2(5):413-7.

56 Carta A, D’Adda T, Carrara F, Zeviani M. Ultrastructural analysis of extraocular muscle in chronic progressive external ophthalmoplegia. Arch Ophthalmol. 2000;118(10):1441-5.

57 Gajek G, Świerzko AS, Cedzyński M. Association of polymorphisms of MASP $1 / 3$, COLEC10, and COLEC11 genes with 3MC syndrome. Int J Mol Sci. 2020;21(15):5483.

58 Sybert VP, McCauley E. Turner's syndrome. N Engl J Med. 2004;351(12):1227-38.

59 Roberts AE, Allanson JE, Tartaglia M, Gelb BD. Noonan syndrome. Lancet. 2013; 381(9863):333-42.

60 Yates TM, Turner CL, Firth HV, Berg J, Pilz DT. Baraitser-Winter cerebrofrontofacial syndrome. Clin Genet. 2017;92(1):3-9.

61 Wang YR, Xu NX, Wang J, Wang XM. Kabuki syndrome: review of the clinical features, diagnosis and epigenetic mechanisms. World J Pediatr. 2019;15(6):528-35.
62 Flex E, Ciolfi A, Caputo V, Fodale V, Leoni C, Melis D, et al. Loss of function of the E3 ubiquitin-protein ligase UBE3B causes Kaufman oculocerebrofacial syndrome. J Med Genet. 2013;50(8):493-9.

63 Engle EC. Human genetic disorders of axon guidance. Cold Spring Harb Perspect Biol. 2010;2(3):a001784.

64 Gaur N, Sharma P. Management of Duane retraction syndrome: a simplified approach. Indian J Ophthalmol. 2019;67(1):16-22.

65 Vulto-van Silfhout AT, de Vries BB, van Bon BW, Hoischen A, Ruiterkamp-Versteeg M, Gilissen C, et al. Mutations in MED12 cause X-linked Ohdo syndrome. Am J Hum Genet. 2013;92(3):401-6.

66 Todd JJ, Sagar V, Lawal TA, Allen C, Razaqyar MS, Shelton MS, et al. Correlation of phenotype with genotype and protein structure in RYR1-related disorders. J Neurol. 2018; 265(11):2506-24

67 McMillin MJ, Below JE, Shively KM, Beck AE, Gildersleeve HI, Pinner J, et al. Mutations in ECEL1 cause distal arthrogryposis type 5D. American journal of human genetics. 2013; 92(1):150-6.

68 Yang A, Kim J, Cho SY, Lee JE, Kim HJ, Jin DK. A case of de novo 18p deletion syndrome with panhypopituitarism. Ann Pediatr Endocrinol Metab. 2019;24(1):60-3.

69 Møller RS, Jensen LR, Maas SM, Filmus J, Capurro $\mathrm{M}$, Hansen $\mathrm{C}$, et al. X-linked congenital ptosis and associated intellectual disability, short stature, microcephaly, cleft palate, digital and genital abnormalities define novel Xq25q26 duplication syndrome. Hum Genet. 2014;133(5):625-38.

70 Castiglione A, Guaran V, Astolfi L, Orioli E, Zeri G, Gemmati D, et al. Karyotype-phenotype correlation in partial trisomies of the short arm of chromosome 6: a family case report and review of the literature. Cytogenet Genome Res. 2013;141(4):243-59.

71 Broomfield A, Sweeney MG, Woodward CE, Fratter C, Morris AM, Leonard JV, et al. Paediatric single mitochondrial DNA deletion disorders: an overlapping spectrum of disease. J Inherit Metab Dis. 2015;38(3): 445-57.

72 Kraft M, Cirstea IC, Voss AK, Thomas T, Goehring I, Sheikh BN, et al. Disruption of the histone acetyltransferase MYST4 leads to a Noonan syndrome-like phenotype and hyperactivated MAPK signaling in humans and mice. J Clin Invest. 2011;121(9):3479-91.

73 Mattioli F, Schaefer E, Magee A, Mark P, Mancini GM, Dieterich K, et al. Mutations in histone acetylase modifier BRPF1 cause an autosomal-dominant form of intellectual disability with associated ptosis. Am J Hum Genet. 2017;100(1):105-16. 